\title{
WHICH IS THE FAIR SEX? GENDER DIFFERENCES IN ALTRUISM*
}

\author{
JAMES ANDREONi AND Lise Vesterlund
}

We study gender differences in altruism by examining a modified dictator game with varying incomes and prices. Our results indicate that the question "which is the fair sex?" has a complicated answer-when altruism is expensive, women are kinder, but when it is cheap, men are more altruistic. That is, we find that the male and female "demand curves for altruism" cross, and that men are more responsive to price changes. Furthermore, men are more likely to be either perfectly selfish or perfectly selfless, whereas women tend to be "equalitarians" who prefer to share evenly.

\section{INTRODUCTION}

Are women more altruistic than men? Is one sex more fair than the other? If there are systematic differences in altruism by sex, then economic theorists will see new predictions from models on, for instance, charitable giving, bargaining, and household decision making. For empirical researchers, such sex differences may influence views on the charitable deduction, intergenerational transfers, or the allocations among spouses resulting from household bargaining. While the implications of sex differences in altruism have gone largely unexplored by economists, there are some preliminary indications that such differences may be important. During the past decade, for instance, researchers have noticed that males and females have different patterns of charitable giving, with each sex favoring different types of charities and influenced by different factors. ${ }^{1}$ In addition, fundraisers for charity have come to realize the substantial giving potential of female donors and are designing sex-specific solicitation strategies. $^{2}$ Policy makers, too, have noted gross sex differences in philanthropy, with women apparently more responsive to the

* We are grateful to Yannis Bilias, Gary Bolton, Gary Charness, Michael Conlin, Rachel Croson, Steven Durlauf, Catherine Eckel, Elizabeth Hoffman, Catherine Kling, Michael Lynn, and Bradley Ruffle for helpful comments and conversations. We thank Isaac Rischall for expert research assistance. In addition, we acknowledge the National Science Foundation for financial support.

1. Eller [1997] discusses estate giving, and Andreoni, Brown, and Rischall [1999] discuss annual giving. Both studies, which will be discussed more later, show significant differences in male and female giving.

2. It has even been claimed that "Women in philanthropy is the hottest topic in fundraising today" [Panas 1994]. For discussions of female donors see Von Schlegell and Fisher [1993], Ostrander and Fisher [1995], and Ostrower [1995].

๑ 2001 by the President and Fellows of Harvard College and the Massachusetts Institute of Technology.

The Quarterly Journal of Economics, February 2001 
need for charitable giving. ${ }^{3}$ Such systematic differences could affect economists' models, data analyses, and research methodologies whenever altrusim may be a factor in decisions.

A natural place to look for sex differences is in controlled laboratory experiments. While economic experiments have found great variation in altruism among individuals, no consensus has emerged on gender as an explanatory variable. ${ }^{4}$ In public goods games, for example, some have found all-male groups to be more cooperative than all-female groups, and others have found the opposite. ${ }^{5}$ In ultimatum bargaining games, men and women were found to be no different in the offers they make, but women are more willing to accept unfair offers than men. ${ }^{6}$ In the dictator game, there are also mixed results, with some finding no differences by sex, while others find all-female groups to be more generous than all-male groups. ${ }^{7}$

We take a new look at gender and altruism by asking how male and female "demands for altruism" may differ. To focus on altruism apart from strategic concerns, we look at the dictator game, and rather than looking at a single choice as others have done, we observe individual giving decisions on different budgets with different "prices of altruism." Hence, we can identify gender differences based on both the levels and variations in the price of giving.

Our results provide a potential for explaining and unifying the variety of results in other studies. In particular, we find that when it is relatively expensive to give, women are more generou than men; however, as the price of giving decreases, men begin to give more than women. That is, male and female demand curves for altruism cross, and men are more responsive to price changes.

3. One such interesting gender difference occurred during a recession in 1991, when women increased their philanthropic giving by 2.4 percent, while men decreased their contributions by just over 20 percent [Mixer 1993].

4. For the vast variation across subjects, see, for example, Isaac, Walker, and Williams [1994], Andreoni [1993, 1995], and Andreoni and Miller [1998]. For an excellent and comprehensive review of the results on gender difference, see Eckel and Grossman [1998].

5. Brown-Kruse and Hummels [1993] find male groups to be more cooperative, while Nowell and Tinkler [1994] find female groups to be more cooperative.

6. See Eckel and Grossman [1997a]. Also, Solnick [1997] finds no significant gender differences in offer or rejection rates, but does find that subjects expect female partners to be more cooperative.

7. Bolton and Katok [1995] find no significant male-female differences, while Eckel and Grossman [1997b] find all-female groups are more altruistic than all-male groups. Experiments by psychologists and other social scientists have, like economists, also found varying results, with either sex sometimes seen as more altruistic. See Eagly [1995] for a review of psychology evidence. 
In addition, men are more likely to be either perfectly selfish or perfectly selfless, whereas women tend to be "equalitarians" who prefer to share evenly-a result that echoes psychological findings. In sum, we find that the question "which is the fair sex?" has a complicated answer-depending on the price, either sex may be seen as more fair.

The next section of this paper presents the experimental design. We then present the results in three parts. First, we look for evidence of gender differences in the raw data. Next we characterize that difference in an economic framework, and provide a predictive model of behavior by sex. Third, we compare our results with past experimental results on gender differences. The paper ends with a discussion of some of the potential implications of our findings.

\section{EXPeRIMENTAL DesigN}

The experiment was conducted at the University of Wisconsin and at Iowa State University. The subjects were volunteers from intermediate and upper level economics courses. The experiments at both universities consisted of two experimental sessions. At Wisconsin both sessions consisted of 35 subjects, while the two at Iowa State contained 38 and 34 subjects each, for a total of 142 subjects. The experiment lasted less than an hour, and subjects earned an average of $\$ 9.60$.

We placed no emphasis on gender when recruiting or running the experiment. This differs from others who compared all-male with all-female groups. This was done to avoid unwanted psychological influences, such as "in-group" effects, and to get a picture of the male-female difference that would naturally occur in an experiment not designed to test for such differences. As a result, approximately two-thirds of our subject pool was male. ${ }^{8}$

The experiment employed a modification of the dictator game. ${ }^{9}$ In this game a subject decides how to allocate a fixed payoff between himself and another subject, over a series of different "budgets" of payoffs, with different relative prices of own-payoff and other-payoff. This then allows us to look at indi-

8. At Wisconsin 49 of the 70 subjects were male, and at Iowa State 46 of 72 were male.

9. A copy of the instructions used is given in the Appendix. 
vidual demand curves, and hence discuss variation both within and across subjects.

It is important to note that this experiment was originally conducted to examine whether preferences for altruism are consistent with the axioms of revealed preference, such as GARP. The results, reported in Andreoni and Miller [1998], indicate that indeed a simple neoclassical framework with well-behaved preferences for giving can be used to describe the data. This paper extends their work to whether demands differ by sex.

Each session of the experiment was conducted by first assembling all the subjects in a very large lecture hall, being careful to keep subjects separated. The subjects were then given an envelope containing their instructions, a pencil, and a "claim check" with their identification number on it. The subjects used the claim check to collect their "earnings envelope" at the end of the experiment. The procedures guaranteed that neither the subjects nor the experimenter could link anyone to their choices.

The subjects were told that their task was to allocate a fixed number of tokens between themselves and an anonymous person randomly chosen from the group. All subjects were given eight different allocation problems and were asked to make an allocation decision in each of them. ${ }^{10}$ They were told that the experimenter would choose one of the problems at random and carry out the subject's decision with another randomly chosen subject as the recipient. Each of the decision problems differed in the number of tokens to be divided and the number of points a token was worth to each subject. All subjects were given the same set of decision problems, although the order of the problems was randomized for each subject. Tokens were worth either 1,2 , or 3 points each, and total tokens available was either $40,60,75$, or 100. For each decision problem, subjects were told they could hold tokens or pass them to the other player. Subjects made their decision by filling in the blanks in the statements like the following: "Divide 60 tokens: Hold at 1 point each, and Pass at 2 points each." Finally, subjects were told that each point earned would be worth $\$ 0.10$ in payoff, hence 75 points would earn $\$ 7.50$. Each of the eight problems is listed in Table I.

Notice that the values of the tokens can be used to calculate

10. While it is of interest to solicit a very large number of decisions, we wanted to secure the subjects a reasonable expected return from each decision; hence the number of allocation problems was limited to eight. 
TABLE I

Allocation CHOices

\begin{tabular}{cccccc}
\hline \hline Budget & $\begin{array}{c}\text { Token } \\
\text { endowment }\end{array}$ & $\begin{array}{c}\text { Hold } \\
\text { value }\end{array}$ & $\begin{array}{c}\text { Pass } \\
\text { value }\end{array}$ & $\begin{array}{c}\pi_{s} \\
\text { Price }\end{array}$ & $\begin{array}{c}\pi_{o} \\
\text { Price }\end{array}$ \\
\hline 1 & 40 & 1 & 3 & 1.00 & 0.33 \\
2 & 60 & 1 & 2 & 1.00 & 0.50 \\
3 & 75 & 1 & 2 & 1.00 & 0.50 \\
4 & 60 & 1 & 1 & 1.00 & 1.00 \\
5 & 100 & 1 & 1 & 1.00 & 1.00 \\
6 & 60 & 2 & 1 & 0.50 & 1.00 \\
7 & 75 & 2 & 1 & 0.50 & 1.00 \\
8 & 40 & 3 & 1 & 0.33 & 1.00 \\
\hline \hline
\end{tabular}

the subjects' budgets in terms of payoffs. Consider Budget 1. In this case, transferring a token raises the other subject's payoff $\pi_{o}$ by 3 points, and reduces one's own payoff $\pi_{s}$ by 1 , implying that the price of the opponent's payoff, $p_{o}$, is 0.33 and the price of self-payoff, $p_{s}$, is 1 . In this way we can think of the token endowment as an income variable, the price of self-payoff as the inverse of the hold value, and the price of other-payoff as the inverse of the pass value.

In order to pool the data from the University of Wisconsin with those from Iowa State University, we must be sure that the potential results are due to gender differences and not to institutional differences. When comparing mean giving for each sex and budget, one cannot reject the hypothesis that generosity is the same at Wisconsin as at Iowa State. Thus, the samples were pooled for our analysis, creating a combined sample of 47 female subjects and 95 male subjects.

\section{RESULTS}

We will report the results in two parts. First, we will look at the raw data for evidence of male and female differences. Second, we will characterize that difference in an economically meaningful way, that is, through utility, demand curves, and elasticity.

\section{III.A. Is There a Male-Female Difference?}

Across the eight budgets men on average passed $\$ 2.56$ (s.d. 1.18 ) to the other player, while women passed an average of $\$ 2.60$ 
TABLE II

MeAn Payoff to Other PARTy

\begin{tabular}{cccccccr}
\hline \hline Budget & $\begin{array}{c}\text { Token } \\
\text { endowment }\end{array}$ & $\begin{array}{c}\text { Income } \\
m\end{array}$ & $p_{o} / p_{s}$ & $\begin{array}{c}\text { All } \\
\text { subjects }\end{array}$ & $\begin{array}{c}\text { Male } \\
\text { subjects }\end{array}$ & $\begin{array}{c}\text { Female } \\
\text { subjects }\end{array}$ & $t$-stat \\
\hline 1 & 40 & 4.00 & $1 / 3$ & 3.79 & 4.18 & 3.01 & 1.96 \\
2 & 60 & 6.00 & $1 / 2$ & 4.02 & 4.30 & 3.49 & 1.48 \\
3 & 75 & 7.50 & $1 / 2$ & 4.68 & 5.00 & 4.03 & 1.53 \\
4 & 60 & 6.00 & 1 & 1.54 & 1.36 & 1.91 & -2.26 \\
5 & 100 & 10.00 & 1 & 2.52 & 2.33 & 2.92 & -1.42 \\
6 & 60 & 12.00 & 2 & 1.42 & 1.21 & 1.82 & -2.07 \\
7 & 75 & 15.00 & 2 & 1.71 & 1.42 & 2.29 & -2.35 \\
8 & 40 & 12.00 & 3 & 0.89 & 0.67 & 1.32 & -2.97 \\
\hline Average & & & & 2.57 & 2.56 & 2.60 & -0.24 \\
\hline \hline
\end{tabular}

(s.d. 0.83). This difference is not significant $(t=0.24)$, indicating that on average males and females are very similar. ${ }^{11}$ This simple comparison of sample means across the eight budgets, however, is quite misleading.

In Table II we show the choices across each of the budgets. Here we express the budgets by choosing own-payoff $\pi_{s}$ as the numeraire, and letting $p=p_{o} / p_{s}$ be the relative price of giving to the other subjects, and letting real income $m$ be the token endowment divided by $p_{s}$. When examining the mean giving across individual budgets, we see large differences between males and females. First, when the relative price changes in favor of giving, both males and females increase the payoff passed; however, they do so in two entirely different manners. Men on average increase the proportion of tokens given, whereas women decrease the proportion. The resulting range of payoff passed is therefore larger for males than for females. Second, neither gender is uniformly more altruistic than the other. Women appear less generous than men when the price of other-payoff, $p_{o}$, is lower than the price of self-payoff, $p_{s}$, while the opposite holds when the relative price of giving is greater than or equal to one. This difference is significant when the relative price of giving is larger than one, and is marginally significant when the relative price is less than one. ${ }^{12}$

11. With 8 budgets and 142 subjects, $N=1136$.

12. The $p$-value of a one-tailed test is 0.026 for Budget 1, 0.07 for Budget 2, and 0.063 for Budget 3 . 


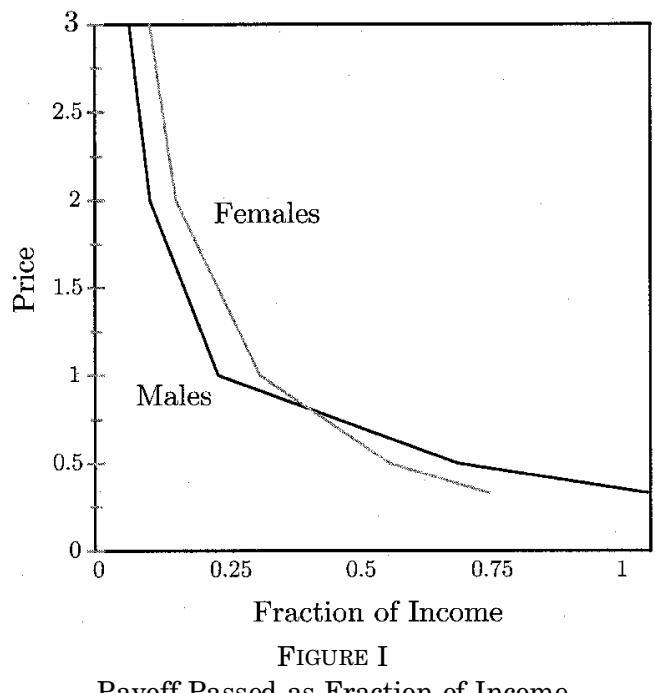

Payoff Passed as Fraction of Income

Figure I illustrates this finding by showing the amount of income passed as a fraction of own income, $m$. Note that $m$ is the amount one would earn by passing nothing to the other subject. We can see that this curve, which is not a proper demand curve, is flatter for males than for females, and that the male curve crosses the female curve from below. That is, for men the ratio of payoff passed to income is more sensitive to price than it is for women. ${ }^{13}$

\section{III.B. An Economic Statement of the Difference}

One can conceptualize these differences by assuming that subjects have well-behaved preferences of the form $U_{s}=U_{s}\left(\pi_{s}, \pi_{o}\right)$ over the budget $\pi_{s}+p \pi_{o}=m$, where $p$ denotes the relative price of giving, $p_{o} / p_{s}$, and $m$ denotes the real value (in units of $\pi_{s}$ ) of a given token endowment. This implies that we can view the payoff passed, $\pi_{o}$, as resulting from a demand function $\pi_{o}=\pi_{o}(p, m)$.

Using this approach, the gender difference in price respon-

13. The data for budgets with the same relative price were pooled for this analysis. An examination of payoff passed as proportion of income demonstrates that for a given price we cannot reject the hypothesis that the allocated income has no effect on the proportion of payoff passed (for females the $p$-value is 0.60 at $p_{o} / p_{s}=1 / 2,0.56$ at $p_{o} / p_{s}=1$, and 0.98 at $p_{o} / p_{s}=2$; for males the $p$-value is 0.58 at $p_{o} / p_{s}=1 / 2,0.87$ at $p_{o} / p_{s}=1$, and 0.74 at $\left.p_{o} / p_{s}=2\right)$. 
siveness can be viewed as a difference in the price elasticity of demand. Holding income constant and comparing the individual demands at two different price levels, we can calculate the arc price elasticity for each individual. There are two such possible comparisons, and for both of these we find that the average of the female price elasticity is smaller than it is for males. At an income of $\$ 12.00$ and for an increase in price from $p=2$ to $p=3$, the average price elasticity for men is -1.03 , and that for women is -0.60 . At an income of $\$ 6.00$ and for a price increase of $p=1 / 2$ to $p=1$, the result is similar; the average price elasticity for males is -1.12 , and for females it is -0.70 . In both cases the difference is significant. ${ }^{14}$ While the male demand on average is elastic, that of females is inelastic.

Another way to look at sex differences is to examine the variation within a subject. A closer look at the data (see Andreoni and Miller [1998]) reveals that there are three behavioral clusters consistent with behavior under three different utility functions. First, some subjects chose to free-ride and to pass no tokens; hence it is likely that their objective function is of the form, $U^{f}\left(\pi_{s}, \pi_{o}\right)=\pi_{s}$. Second, others chose to provide each participant with equal payoffs, implying behavior consistent with that of a Leontief utility function $U^{l}\left(\pi_{s}, \pi_{o}\right)=\min \left\{\pi_{s}, \pi_{o}\right\}$. Finally, a group of males allocated their tokens to the person with the highest redemption value, implying that a utility function of perfect substitutes, $U^{p}\left(\pi_{s}, \pi_{o}\right)=\pi_{s}+\pi_{o}$, can rationalize their behavior. With these three "strong" cases, we can exactly describe the choices of 47 percent of the male subjects and 36 percent of the females. The remaining subjects did not easily fit these wellknown cases. Instead, by minimizing the Euclidean distance between the actual behavior and the behavior predicted by one of the three utility functions, these subjects can be classified as weakly similar to one of the three utility functions. Table III illustrates the classifications for males and females.

By combining the strong and weak classifications, we see several differences. First, almost half the men are selfish, while

14. A simple $t$-test reveals that the arc price elasticity is smaller for males than for females with a $p$-value of 0.089 when the price increases from 2 to 3 , and with a $p$-value of 0.007 when the price increases from $1 / 2$ to 1 . A practically identical result was found from 10,000 independent bootstrap samples. For a price increase from 2 to 3 we found that only 8.7 percent of 10,000 mean female elasticities were larger than the corresponding mean for men. For a price increase from $1 / 2$ to 1 , only 0.5 percent of the mean elasticities for females were greater than for males. 
TABLE III

SubJECt ClassificAtion By PROTOTYPICAL Utility FUnCTIONa

\begin{tabular}{lccccccc}
\hline \hline & \multicolumn{3}{c}{ Male } & & \multicolumn{3}{c}{ Female } \\
\cline { 2 - 4 } \cline { 7 - 8 } \multicolumn{1}{c}{ Utility function } & Strong & Weak & Total & & Strong & Weak & Total \\
\hline Selfish & 24 & 21 & 45 & & 7 & 10 & 17 \\
Leontief & 13 & 11 & 24 & & 10 & 15 & 25 \\
Perfect substitutes & 8 & 18 & 26 & & 0 & 4 & 4 \\
\hline \hline
\end{tabular}

a. A female subject exactly halfway between strong Leontief and Perfect substitutes is not included in this analysis.

only 36 percent of the women are selfish. Second, men are far more likely to treat other-payoff as a perfect substitute to their own payoff. Finally, the choices of 54 percent of the women resemble behavior most consistent with a Leontief utility function, while only 25 percent of the men appear to have such preferences. These differences are shown in Figure II. As expected, we reject the null hypothesis that the utility function classification is independent of gender $\left(\chi_{[2]}^{2}=13.39, \alpha<0.001\right) .{ }^{15}$ In particular, men are more likely to be either perfectly selfish or to maximize total payoffs of both subjects, while women are more likely to insist on equality.

Note that we can use our results to understand gender differences in other experiments by estimating representative demand curves for males and females. Rather than estimating a single aggregate demand curve, we aggregate our own function based on the results presented above.

From Table III we see that three "strong" functional forms of demand can describe nearly half of our subjects. These three are Leontief $(l)$, perfect substitutes $(p)$, and selfish $(f)$. We assume that preferences for these subjects are observed without error, and for each case we solve for an individual demand function, $\pi_{o}^{j}$, $j=l, p, f$.

For the estimation we assume that subjects in the "weak" fitting category have demands of the form, $\pi_{o}^{w}(p, m)=(1-$ $\alpha) \gamma_{2}+\alpha m / p-\alpha \gamma_{1} / p .{ }^{16}$ In estimating this demand function, we

15. Similar results hold when we look at the data as presented in Table III. When determining whether the strong classification is independent of gender $\chi_{[2]}^{2}=6.37$, and for the weak classification $\chi_{[2]}^{2}=8.44$.

16. That is, the underlying preferences are of the Linear Expenditure Model (LEM) form, $U\left(\pi_{s}, \pi_{o}\right)=\left(\pi_{s}-\gamma_{1}\right)^{1-\alpha}\left(\pi_{o}-\gamma_{0}\right)^{\alpha}$. The benefit of using this function 


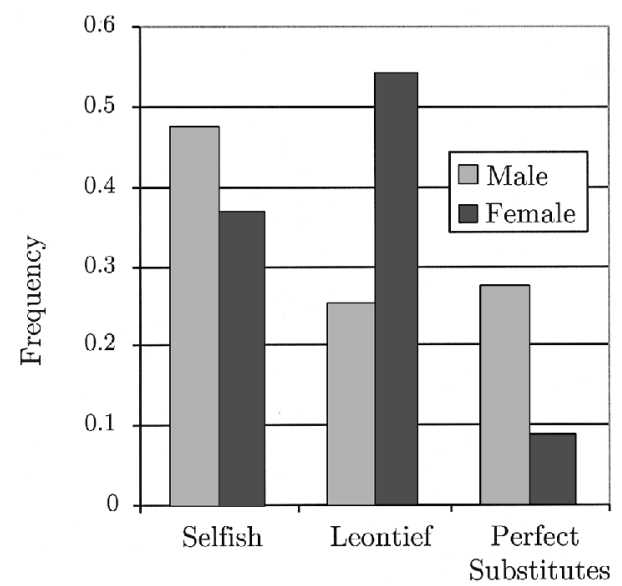

Figure II

Preference Distribution (Strong and Weak)

need to appropriately account for the characteristics of our data. First, subjects' choices are censored at both ends of the budget constraint, and second, our data consist of eight decisions per individual. To appropriately control for both of these features of the data, we estimate a random-effects two-limit tobit model. Finally, the error term was found to be hetereoskedastic when demands were specified in levels. Hence, to assure homoskedasticity, the demands were estimated as budget shares. The results for the weak category are reported in Table IV.

While all the coefficients of the male demand function are significant, only the coefficient on income is significantly different from zero for females. ${ }^{17}$ Comparing the log likelihood functions reveals that the coefficients for men and women in the weak category are significantly different from one another $\left(\chi_{[5]}^{2}=\right.$ 34.81).

We can now combine the individual demand curves to form a weighted demand curve. Let $q_{k}$ be the proportion of subjects in each group $k$. Then the weighted male and female demand functions are

is that it allows us to capture potential gender differences in price as well as income elasticities.

17. For all three regressions we can reject the joint hypothesis that the coefficients equal zero: for females $\chi_{[2]}^{2}=6.7$, for males $\chi_{[2]}^{2}=122.7$, and for all $\chi_{[2]}^{2}=107.7$. 
TABLE IV

ESTIMATES OF WEAK LEM DEMAND FUNCTIONS ${ }^{a}$

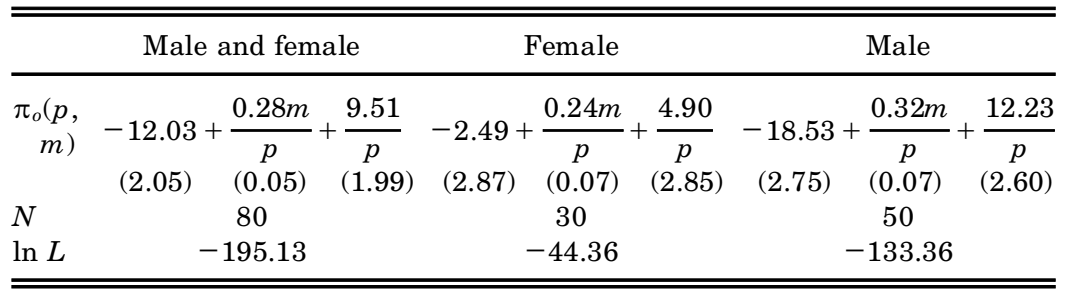

a. Numbers in parentheses are standard errors of the estimates directly above them.

$$
\begin{aligned}
\pi_{o}(p, m)=q_{w} \pi_{o}^{w}(p, m)+ & q_{l} \pi_{o}^{l}(p, m) \\
& +q_{p} \pi_{o}^{p}(p, m)+q_{f} \pi_{o}^{f}(p, m) .
\end{aligned}
$$

Figure III illustrates the two demand functions for $m=100$, which corresponds to predicted demands in a traditional $\$ 10$ dictator game. ${ }^{18}$ Note that we can reject the hypothesis that the demand functions are the same for males and females, with $\chi_{[8]}^{2}=$ 49.54. ${ }^{19}$

As suggested above, the male and female "demand curves for altruism" do indeed cross. At high prices of altruism women demand more; at low prices men demand more; and at prices in between men and women are equally altruistic. Furthermore, the representative male demand curve is more responsive to a price change than the female demand curve. Note that the reason that the male demand curve is not a one-to-one mapping at $p=1$ is that close to 10 percent of the males view own- and other-payoff as perfect substitutes, hence a continuum of demands is optimal at $p=1$.

\section{III.C. Comparison to Other Studies}

Are our findings consistent with prior studies on dictator games? Most other studies have found that subjects, on average,

18. In making these predictions, one must account for the censoring of individual demands.

19. This is a test of the hypothesis that the set of parameters that generate the male demand curve equals that of females. The relevant parameters are the five estimated coefficients from the weak demand curves-including $\sigma_{u}$ and $\sigma_{\epsilon}$, the parameter estimates for the error terms resulting from the random effects tobit estimation-plus the three proportions of subjects in strong preference groups. 


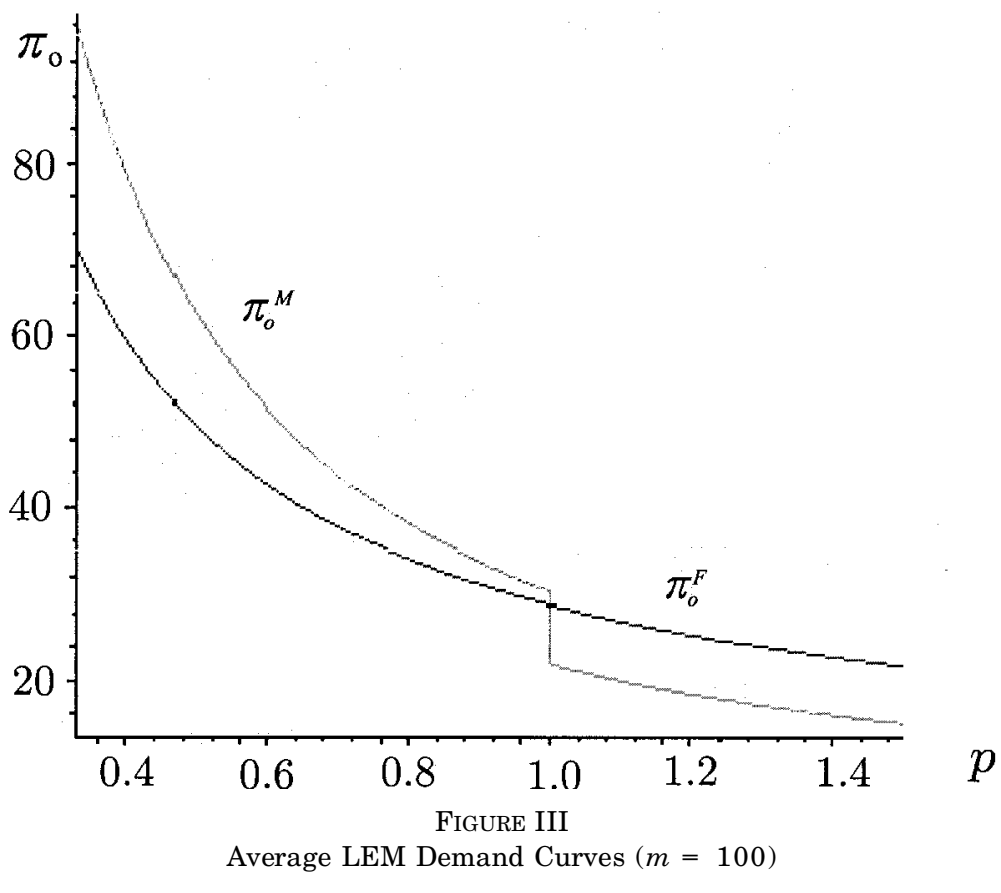

give away about 25 percent of a given pie. ${ }^{20}$ In our $\$ 10.00$ dictator game the average gift is $\$ 2.52$ (25.2 percent), and in the $\$ 6.00$ game the average gift is $\$ 1.54$ (25.6 percent), which successfully replicates earlier studies.

Next, can our results explain the mixed evidence on gender differences from other experiments? While we can make some comparison, there are many differences across experiments that make direct comparisons difficult. In particular, we find the maximum variance in the behavior of men when the price of altruism is unity. Unfortunately, this is the prevailing price in many experiments. So, for instance, the fact that Bolton and Katok [1995] find no sex differences when the price is one is not a surprise in light of our finding. ${ }^{21}$ Nor is it inconceivable that Eckel and Grossman [1997b], comparing all-male with all-female

20. See, for example, Forsythe et al. [1994], Cason and Mui [1997], Bolton, Katok, and Zwick [1998], and Bohnet and Frey [1999a, 1999b].

21. Also, Bolton and Katok [1995] do not allow giving to exceed 50 percent, making comparison to our results more difficult. 
groups with a price of one, find that women are significantly more altruistic.

Finally, Eckel and Grossman [1996], in a sequential game, find that women are, overall, more likely to pay to punish selfishness than are men. In a related study, Croson and Buchan [1999] found that women are more likely to reward generous contributions in the trust game. It is difficult to compare demands for rewards and punishment with our estimates of demand for altruism. However, these findings do show that females have more of an interest in equality and justice, which is very much in sync with our finding that women were more likely to be equalitarians.

\section{Discussion}

What do these results mean for experimental research? First, they indicate that there are systematic differences by sex, and that these can have important and interesting consequences for economic behavior. Second, the results have implications for experimental methodology. In particular, experimenters may need to take greater care in assuring that their studies are gender balanced, and that findings are due to economic factors and not the gender composition of their samples.

Do our results apply outside of experiments? A natural place to look for sex differences in altruism is in charitable giving. For years, public economists have been studying the effect of the charitable deduction for taxpayers, which acts as a subsidy to lower the price of giving. If men and women have systematically different price elasticities, then tax policy could have a different incidence on males than females, and on charities whose donors may vary by sex. Using the 1992 and 1994 surveys by the Independent Sector, Andreoni, Brown, and Rischall [1999] show that one can reject the hypothesis that single men and single women have the same demand functions for annual giving. In startling resemblance to our results they find that the male demand for altruism is more elastic than that of females, and that the two demand curves cross in a way that resembles Figure I above. Similar results hold when comparing male and female "deciders" in married households, where the decider is the spouse who is reported to be primarily responsible for the charitable giving decisions. Again, married male deciders are far more price elastic than married female deciders. 
Another arena for altruism is restaurant tipping. The lore is that women tip less than men. According to recent work by Conlin, O'Donoghue, and Lynn [1999], this depends on, among other things, the size of the bill. These researchers interviewed customers leaving over 40 restaurants in Houston, Texas. The results indicate that people tend to view 15 percent of the bill as the appropriate tip for a server who performs well. As the bill size gets larger, however, meeting this social norm becomes more expensive. What Conlin, O'Donoghue, and Lynn's data reveal is that, in fact, the percent-tip is a decreasing function of the bill size for both men and women and that men's percent-tip is more responsive to the bill size than women's. ${ }^{22}$ All else equal, as the bill size increases, men's percent-tips decline at a faster rate than those of women. For the typical male and female diners, men will tip better than women for small bills, up to about $\$ 27$, but after that the women become better tippers. This is perfectly consistent with our findings in the experiment.

\section{Conclusion}

This study finds that, depending on the price of giving, either sex can be found to be more altruistic. When the price of giving is low, men appear more altruistic, and when the price is high, women are more generous. Stated differently, men are more likely to be either perfectly selfish or perfectly selfless, whereas women care more about equalizing payoffs. This leads to demand curves for altruism that cross and those for men are more price-elastic.

There are several important consequences of this result. First, this finding can potentially unify a literature that has thus far been fractured by inconsistent findings. By showing that differences in altruism depend on the price, we can begin to organize studies that sometimes found men to be more altruistic and sometimes women. Second, this indicates a need for more

22. This finding was communicated to us through personal correspondence from the authors. We deeply appreciate their willingness to provide us with information that relates to the hypothesis of this paper. The estimates are based on a sample of 2141 customers. Independent variables include the bill-size, billsize squared, sex of the customer, and sex interacted with the bill-size, and bill-size squared, age of the customer, group size, courses ordered, alcohol consumption, ratings for quality of food and service, whether the server and customer are the same sex, an indicator of how often the customer dines at that restaurant, in addition to fixed effects for each restaurant. The slope of the estimated response to bill-size is steeper for men for all bills in excess of $\$ 10.26$. 
attention to sex differences in experimental economics. If differences appear with respect to altruism, they may appear in other behavior as well. ${ }^{23}$ This, in turn, means that researchers would be wise to assure that their experimental findings are the result of economic incentives and not of varying sex compositions of their control and treatment groups.

There are also potential applications of this result to the real world. If sex differences in altruism are truly present, as suggested by evidence from charitable giving and from restaurant tipping, then those who broker in altruism, such as charities and fundraisers, may find it in their interests to learn more about these differences and to exploit them in their enterprises. For tax policy, sex difference in altruism may also indicate that the incidence of the tax deduction to charity may differ by sex as well, with men-and the charities they favor-getting a greater share of the subsidy.

In sum, when observable characteristics of individuals have predictable effects on behavior, it presents important opportunities for economists to learn about behavior, as well as important warning signs about how to collect and analyze data. This study gives more evidence to the proposition that gender differences in economic experiments may be one such factor that researchers will have to examine more carefully in the future.

\section{APPENDIX}

Claim Check Number

\section{INSTRUCTIONS}

Welcome

This is an experiment about decision making. You will be paid for participating, and the amount of money you will earn depends on the decisions that you and the other participants make. If you make good decisions, you stand to earn a considerable amount of money.

23. Evidence is rising that there are sex differences in risk aversion as well. See, for example, Levin, Snyder, and Chapman [1988], Hudgens and Fatkin [1985], Zinkhan and Karande [1991], Arch [1993], and Kogan and Wallach [1964]. Recent evidence in the economics literature also supports this finding. See Eckel et al. [1997], Jianakoplos and Bernasek [1998], and Powell and Ansic [1998]. 
The entire experiment should be complete within an hour. At the end of the experiment you will be paid privately and in cash for your decisions. A research foundation has provided the funds for this experiment.

\section{Your Identity}

You will never be asked to reveal your identity to anyone during the course of the experiment. Your name will never be recorded by anyone. Neither the experimenters nor the other subjects will be able to link you to any of your decisions.

In order to keep your decisions private, please do not reveal your choices to any other participant.

\section{Claim Check}

At the top of this page is a number on a yellow piece of paper. This is your Claim Check. Each participant has a different number. You may want to verify that the number on your Claim Check is the same as the number on the top of page 4 .

You will present your Claim Check to an assistant at the end of the experiment to receive your cash payment.

Please remove your claim check now and put it in a safe place.

\section{THIS EXPERIMENT}

In this experiment you are asked to make a series of choices about how to divide a set of tokens between yourself and one other subject in the room. You and the other subject will be paired randomly, and you will not be told each other's identity.

As you divide the tokens, you and the other subject will each earn points. Every point that subjects earn will be worth 10 cents. For example, if you earn 58 points you will make $\$ 5.80$ in the experiment.

Each choice you make is similar to the following:

Example: Divide 50 tokens: Hold ] 1 point each, and Pass 2 points each.

In this choice you must divide 50 tokens. You can keep all the tokens, keep some and pass some, or pass all the tokens. In this example, you will receive 1 point for every token you hold, and the other player will receive 2 points for every token you pass. For example, if you hold 50 and pass 0 tokens, you will receive 50 
points, or $50 \times \$ 0.10=\$ 5.00$, and the other player will receive no points and $\$ 0$. If you hold 0 tokens and pass 50 , you will receive $\$ 0$ and the other player will receive $50 \times 2=100$ points, or $100 \times$ $\$ 0.10=\$ 10.00$. However, you could choose any number between 0 and 50 to hold. For instance, you could choose to hold 29 tokens and pass 21 . In this case you would earn 29 points, or $29 \times$ $\$ 0.10=\$ 2.90$, and the other subject would receive $21 \times 2=42$ points, that is $42 \times \$ 0.10=\$ 4.20$.

Here is another example:

Example: Divide 40 tokens: Hold ] 3 points each, and Pass 1 point each.

In this example every token you hold earns you 3 points, and every token you pass earns the other subject 1 point. Again, each point you earn is worth $\$ 0.10$ to you, and each point the other subject earns is worth $\$ 0.10$ to the other subject.

Important Note: In all cases you can choose any number to hold and any number to pass, but the number of tokens you hold plus the number of tokens you pass $\underline{\text { must }}$ equal the total number of tokens to divide.

Please feel free to use your calculator, or one provided by the experimenter, to calculate points and to assure that all of the tokens have been allocated.

\section{EARNING MONEY IN THIS EXPERIMENT}

You will be asked to make 8 allocation decisions like the examples we just discussed. We will calculate your payments as follows:

After all your decisions forms have been collected, we will shuffle the forms and randomly pair your form with that of another subject in this experiment. Using a table of random numbers, we will select one of your decisions to carry out. You will then get the points you allocated in the "hold" portion of your decision, and the other subject will get the points you allocated on the "pass" portion of your decision. You will then be paired again with a different subject in the experiment. This time we will randomly choose one of the other subject's eight decisions to carry out. The other subject will get the points in the "hold" portion of the decision, and you will get the points in the "pass" portion.

We will then total the points from these two pairings and determine your monetary earnings. These earnings will be placed 
in your earnings envelope. The monitor chosen at the beginning of the experiment will verify that these procedures are followed.

After all the calculations have been made, another experimenter who was not involved in the experiment until this time will ask you to bring up your claim check and will hand you your earnings envelope. This will again help to guarantee your privacy.

On the following page are the 8 choices we would like you to make. Please fill out the form, taking the time you need to be accurate. When all subjects are done, we will collect the forms. Thank you very much. Good luck)

\section{Claim Check Number}

\section{DECISION SHEET}

Directions: Please fill in all the blanks below. Make sure the number of tokens listed under Hold plus the number listed under Pass equals the total number of tokens available. Remember, all points are worth $\$ 0.10$ to all subjects.

1. Divide 40 tokens: Hold @ 3 points each, and Pass

@ 1 point each.

2. Divide 40 tokens: Hold @ 1 points each, and Pass

@ 3 point each.

3. Divide 60 tokens: Hold @ 2 points each, and Pass

@ 1 point each.

4. Divide 60 tokens: Hold @ 2 point each.

5. Divide 75 tokens: Hold

@ 1 point each.

6. Divide 75 tokens: Hold @ 2 point each.

7. Divide 60 tokens: Hold @ 1 points each, and Pass @ 2 points each, and Pass @ 1 point each.

8. Divide 100 tokens: Hold @ 1 points each, and Pass @ 1 points each, and Pass @ 1 point each.

UNIVERSITY OF WISCONSIN

IOWA STATE UNIVERSITY

\section{REFERENCES}

Andreoni, James, "An Experimental Test of the Public Goods Crowding-Out Hypothesis," American Economic Review, LXXXIII (1993), 1317-1327. 
, "Cooperation in Public Goods Experiments: Kindness or Confusion?" American Economic Review, LXXXV (1995), 891-904.

Andreoni, James, Eleanor Brown, and Isaac Rischall, "Charitable Giving by Married Couples: Who Decides and Why Does it Matter?" Working Paper, University of Wisconsin-Madison, 1999.

Andreoni, James, and John H. Miller, "Giving According to GARP: An Experimental Test of the Rationality of Altruism," Working Paper, University of Wisconsin-Madison, 1998.

Arch, Elizabeth C., "Risk-Taking: A Motivational Basis for Sex Differences," Psychological Reports, LXXIII (1993), 3-11.

Bolton, Gary E., and Elena Katok, "An Experimental Test for Gender Differences in Beneficent Behavior," Economics Letters, XVIII (1995), 287-292.

Bolton, Gary E., Elena Katok, and Rami Zwick, "Dictator Game Giving: Rules of Fairness versus Acts of Kindness," International Journal of Game Theory, XXVII (1998), 269-299.

Bohnet, Iris, and Bruno S. Frey, "Social Distance and Other-Regarding Behavior in Dictator Games: Comment," American Economic Review, LXXXIX (1999a), 335-339.

Bohnet, Iris, and Bruno S. Frey, "The Sound of Silence in Prisoner's Dilemma and Dictator Games," Journal of Economic Behavior and Organization, XXXVIII (1999b), 43-57.

Brown-Kruse, Jamie, and David Hummels, "Gender Effects in Laboratory Public Goods Contribution: Do Individuals Put Their Money Where Their Mouth Is?" Journal of Economic Behavior and Organization, XXII (1993), 255-267.

Cason, Timothy N., and Vai-Lam Mui, "A Laboratory Study of Group Polarisation in the Team Dictator Game," Economic Journal, CVII (1997), 1465-1483.

Conlin, Michael, Ted O'Donoghue, and Michael Lynn, "The Economics of Tipping: Implicit Contract, Repeated Game and Behavioral Responses," Working Paper, Cornell University, 1999.

Croson, Rachel, and Nancy Buchan, "Gender and Culture: International Experimental Evidence from Trust Games," American Economic Review, LXXXIX (1999), 386-392.

Eagley, A. H., "The Science and Politics of Comparing Women and Men," American Psychologist, L (1995), 145-158.

Eckel, Catherine C., and Philip Grossman, "The Relative Price of Fairness: Gender Differences in a Punishment Game," Journal of Economic Behavior and Organization, XXX (1996), 143-158.

Eckel, Catherine C., and Philip Grossman, "Chivalry and Solidarity in Ultimatum Games," Working Paper, Virginia Polytechnic Institute and State University, 1997a.

Eckel, Catherine C., and Philip Grossman, "Are Women Less Selfish than Men? Evidence from Dictator Experiments," Economic Journal, CVII (1997b), $726-735$.

Eckel, Catherine C., and Philip Grossman, "Differences in the Economic Decisions of Men and Women: Experimental Evidence," forthcoming, Handbook of Results in Experimental Economics, C. Plott and V. Smith, eds. (Amsterdam: North-Holland, 1998).

Eckel, Catherine C., Philip Grossman, Nancy Lutz, and V. Padmanbhan, "Playing It Safe: Men, Women, and Risk Aversion," Working Paper, Virginia Polytechnic Institute and State University, 1997.

Eller, Martha Britton, "Federal Taxation of Wealth Transfers," Statistics of Income Bulletin, (1997), 8-63.

Forsythe, Robert, Joel Horowitz, N. S. Savin, and Martin Sefton, "Fairness in Simple Bargaining Games," Games and Economic Behavior, VI (1994), 347-369.

Hudgens, Gerald A., and Linda Torsani Fatkin, "Sex Differences in Risk Taking: Repeated Sessions on a Computer-Simulated Task," Journal of Psychology, CXIX (1985), 197-206.

Isaac, R. Mark, James M. Walker, and Arlington W. Williams, "Group Size and the Voluntary Provision of Public Goods: Experimental Evidence Utilizing Large Groups," Journal of Public Economics, LIV (1994), 1-36. 
Jianakoplos, Nancy Ammon, and Alexandra Bernasek, "Are Women More Risk Averse?" Economic Inquiry, XXXVI (1998), 620-630.

Kogan, Nathan, and Michael A. Wallach, Risk Taking: A Study in Cognition and Personality, (New York: Holt, Rinehart and Winston 1964).

Levin, Irwin P., Mary A. Snyder, and Daniel P. Chapman, "The Interaction of Experiential and Situational Factors and Gender in a Simulated Risky Decision-Making Task," Journal of Psychology, CXXII (1988), 173-181.

Mixer, Joseph R., Principles of Professional Fundraising (San Francisco, CA: Jossey-Bass Inc., 1993).

Nowell, Clifford, and Sarah Tinkler, "The Influence of Gender in the Provision of a Public Good," Journal of Economic Behavior and Organization, XXV (1994), 25-36.

Ostrander, Susan A., and Joan M. Fisher, "Women Giving Money, Women Raising Money: What Difference for Philanthropy?" Charles H. Hamilton and Warren F. Ilchman, eds., Cultures of Giving II: How Heritage, Gender, Wealth, and Values Influence Philanthropy, New Directions for Philanthropic Fundraising, No. 8 (1995).

Ostrower, Francie, Why the Wealthy Give: The Culture of Elite Philanthropy (Princeton, NJ: Princeton University Press, 1995).

Panas, J., "Are Women Donors Really Different fom Men?" Chronicle of Philanthropy (February 8, 1994), 43.

Powell, Melanie, and David Ansic, "Gender Differences in Risk Behavior in Financial Decision-Making: An Experimental Analysis," Working Paper, University of Leeds, United Kingdom, 1998.

Solnick, Sara J., "Gender Differences in the Ultimatum Game," Working Paper, University of Miami, 1997.

Von Schlegell, A. J., and Fisher, J. M., eds., "Women as Donors, Women as Philanthropists," New Directions for Philanthropic Fundraising, No. 2 (1993).

Zinkhan, George M., and Kiran W. Karande, "Cultural and Gender Differences in Risk-Taking Behavior Among American and Spanish Decision Makers," Journal of Social Psychology, CXXXI (1991), 741-742. 